\title{
Phosphorus removal performance and speciation in virgin and modified argon oxygen decarburisation slag designed for wastewater treatment
}

ARTICLE in WATER RESEARCH · SEPTEMBER 2015

Impact Factor: 5.53 · DOI: 10.1016/j.watres.2015.09.035

READS

30

4 AUTHORS, INCLUDING:

Gunno Renman

KTH Royal Institute of Technology 46 PUBLICATIONS 434 CITATIONS

SEE PROFILE

Agnieszka Renman

KTH Royal Institute of Technology

13 PUBLICATIONS 207 CITATIONS

SEE PROFILE
Jon Petter Gustafsson

Swedish University of Agricultural Sciences

94 PUBLICATIONS 2,193 CITATIONS

SEE PROFILE 
NOTICE: this is the author's version of a work that was accepted for publication in Water Research. A definitive version was subsequently published in Water Research 87, 271-281, 2015.

http://dx.doi.org/10.1016/j.watres.2015.09.035

(C) 2015, Elsevier. Licensed under the Creative Commons Attribution-NonCommercial-NoDerivatives 4.0 International http://creativecommons.org/licenses/by-nc-nd/4.0.

\title{
Phosphorus removal performance and speciation in virgin and modified argon oxygen decarburisation slag designed for wastewater treatment
}

\author{
Minyu Zuo ${ }^{a}$, Gunno Renman ${ }^{\text {a }}$ Jon Petter Gustafsson ${ }^{a, b}$, Agnieszka Renman ${ }^{a}$

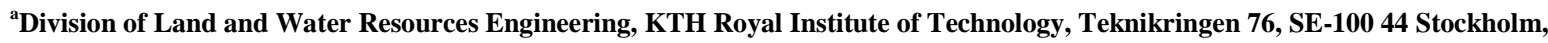 \\ Sweden \\ ${ }^{\mathrm{b}}$ Department of Soil and Environment, Swedish University of Agricultural Sciences, Box 7014, SE-750 07 Uppsala, Sweden
}

\begin{abstract}
Argon oxygen decarburisation (AOD) slag may be used for phosphorus (P) removal, as its high pH and weatherable calcium (Ca) minerals provide sufficient $\mathrm{Ca}^{2+}$ and $\mathrm{OH}^{-}$for calcium phosphate $\left(\mathrm{Ca}-\mathrm{PO}_{4}\right)$ precipitation. This study examined the P removal performance of AOD slag for use as wastewater treatment material. Batch experiments were carried out using both synthetic P solution and real wastewater, followed by chemical modelling and X-ray absorption near edge structure (XANES) spectroscopy. The influences of initial $\mathrm{P}$ concentration, slag dose and modification by polyethylene glycol (PEG), an effective agent for generation of ${ }^{\star}$ Corresponding author. E-mail addresses: minyu@kth.se (M. Zuo), gunno@kth.se (G. Renman), qustafjp@kth.se (J. P. Gustafsson), agak@kth.se (A. Renman).
\end{abstract}


porous materials, were investigated to determine the optimal conditions for P removal by AOD slag. It was found that virgin AOD slag removed 94.8\% of P from a synthetic P solution in 4 hours and $97.8 \%$ in 10 hours. This high P removal was accompanied by a rapid increase in $\mathrm{pH}$ from 7.0 to 10.74 . The maximum P removal capacity (PRC) from synthetic P solution ranged from 1.3 to $27.5 \mathrm{mg} \mathrm{P} \mathrm{g}^{-1}$. The optimal AOD dose for P removal from wastewater, determined in 8-hour batch experiments, was $25 \mathrm{~g} \mathrm{~L}^{-1}$. PEG modification increased the reaction rate and resulted in higher final $\mathrm{pH}$, increasing PRC by 47.9\%. Combined Visual MINTEQ and XANES analysis for detailed examination of $\mathrm{P}$ removal mechanisms revealed that the main $\mathrm{P}$ removal mechanism was precipitation of calcium phosphate. According to the XANES analysis, the main $\mathrm{Ca}-\mathrm{PO}_{4}$ precipitate formed on virgin AOD slag under low initial $\mathrm{P}$ concentration and high $\mathrm{pH}$ was apatite, while brushite was the dominant product at high initial P concentration and low $\mathrm{pH}$.

Keywords: phosphorus, slag, apatite, brushite, Visual MINTEQ, XANES,

\section{Introduction}

Phosphorus (P) removal and recovery from wastewater is an important issue because of the rapid depletion of existing irreplaceable and indispensable P resources (Reijnders 2014). A variety of physical, chemical and biological techniques have been developed and introduced to remove and recover P from wastewater. It is reported that a P recovery of $>90 \%$ can be achieved by technologies such as acidic-alkaline sequential treatment (Petzet et al. 2012) and combined low pressure wet oxidation and nanofiltration (Blöcher et al. 2012). Although 
a high P recovery can be achieved with these technologies, it is also desirable if alternative systems that are more energy- and cost-efficient are developed.

Phosphorus precipitation using slag for P removal and recovery from wastewater involves the capture of phosphate by reaction with metal cations dissolved from slag composed of calcium-rich oxides and silicates. It is considered an economical and effective technology for P removal from wastewater (Drizo et al. 2006, Kim et al. 2006, Gustafsson et al. 2008, Claveau-Mallet et al. 2013). So far, most research on P removal using slag has focused on: blast furnace (BF) slag, which is produced from the separation of iron from ore; electric arc furnace (EAF) slag, which is from the first step of stainless steel production; and blast oxygen furnace (BOF) slag, from the second processing step of carbon steel production (Santos et al. 2013a). The principal advantages of these slags are their wide availability and low cost due to their huge annual production volumes. Although they are byproducts of different processes and their chemical composition varies, they share features such as high calcium content and alkalinity, which makes them favourable for $\mathrm{P}$ removal as they can provide sufficient $\mathrm{Ca}^{2+}$ and $\mathrm{OH}^{-}$ for the formation of calcium phosphate $\left(\mathrm{Ca}-\mathrm{PO}_{4}\right)$ precipitates.

The most widely studied slag, BF slag, has been found to have a P removal efficiency (PRE) higher than 95\% in laboratory experiments with both synthetic P solution and real wastewater (Oguz 2004, Kostura et al. 2005, Rastas 2006, Johansson 2010, Johansson Westholm 2010). However its performance in pilot and field trials is less satisfactory, with P removal reported to range from $40 \%$ to $77 \%$ (Shilton et al. 2006, Asuman et al. 2007). Drizo et al. (2006) conducted column experiments to investigate the P removal performance of EAF slag and obtained consistently high PRE for 114 days. Bowden et al. (2009) investigated BOF slag as a reactive medium 
for P removal in both batch and continuous flow experiments for 406 days and observed high maximum $\mathrm{P}$ removal. Barca et al. (2012) evaluated EAF and BOF slags from four countries in Europe in terms of their P removal capacity using both synthetic P solution and real wastewater and found that BOF slag has a much higher maximum P removal capacity (PRC) than EAF slag. To our knowledge, research using argon oxygen decarburisation (AOD) stainless steel slag for P removal has not been reported previously.

As a by-product from the argon oxygen decarburisation refining process, $270 \mathrm{~kg}$ AOD slag are produced for every ton of stainless steel produced. The slag is mainly applied in cement production, road construction, civil engineering work, fertiliser production and landfill daily cover (Huaiwei and Xin 2011). These do not completely consume the huge production voume and hence increasing amounts of AOD slag are accumulating. Alternative uses of AOD slag are therefore being investigated. AOD slag is reported to have a high alkalinity and to contain more than $35 \%$ Ca in the form of easily soluble calcium silicate (Kriskova et al. 2012, Santos et al. 2013a, Santos et al. 2013b). Hence it may be a promising wastewater treatment material for P removal and recovery via $\mathrm{Ca}-\mathrm{PO}_{4}$ precipitation.

It has been pointed out that the formation of calcium phosphates depends strongly upon the dissolution of calcium silicate from the slag. If BF slag is modified in an effective way the PRE is higher, since the modified slag surface with its higher porosity tends to release more $\mathrm{Ca}^{2+}$ and thus facilitate the precipitation of calcium phosphate (Gong et al. 2009). Inspired by previous research (Guan et al. 2014), a modification process using polyethylene glycol (PEG) was developed in this study, aimed at improving the P removal performance of AOD slag. PEG is a hydrophilic, non-toxic and water-miscible polymer used in controlled-release systems and in 
nanoparticle preparation (Ali and Lamprecht 2013, García-Jimeno and Estelrich 2013). It is produced in an industrial scale and low grade forms are available to a realistic price. In this study, it was mixed with AOD slag under hydrothermal conditions in order to facilitate the dissolution of $\mathrm{Ca}^{2+}$ by converting the original sparingly soluble calcium silicate species on the slag surface into more easily soluble forms.

This study explored P removal by AOD slag in an effort to devise a technically and economically feasible treatment solution that makes it possible to use this metallurgical by-product in wastewater treatment. To obtain reliable results when assessing AOD as a P removal material, batch experiments with both synthetic $\mathrm{P}$ solution and real wastewater were conducted to investigate the PRE and PRC of AOD. The influence of initial P concentration, slag dose and modification by PEG was investigated to determine the optimal conditions that maximise the PRC and P removal efficiency (PRE) of AOD slag. Visual MINTEQ and X-ray absorption near edge structure (XANES) spectroscopic analysis were combined for an in-depth study of the $\mathrm{P}$ removal mechanisms.

\section{Materials and methods}

\subsection{Material}

The AOD slag used in this study was obtained from Outokumpu Stainless AB, Sweden. This slag is porous and has a brown colour. The $\mathrm{pH}$, determined by immersing the AOD slag in distilled water with a volume ratio of 1:2.5 for 24 hours, was found to be 12.04. Chemical analysis revealed that the AOD contained $380 \mathrm{mg}^{\mathrm{Ca}} \mathrm{g}^{-1}$ and $150 \mathrm{mg} \mathrm{Si} \mathrm{g}^{-1}$ (Table 1). The slag was crushed by hand in a mortar and sieved to get particle size fractions of 1-2 mm, 0.5-1 mm (labelled cAOD) and 0-0.5 mm (labelled fAOD). The last two fractions were used only for 
PEG modification. The particle size fraction of 1-2 mm was used in all other experiments because it is expected to be useful in practical applications. A wax-like PEG manufactured by Merck, with a molecular weight ranging from 950 to $1050 \mathrm{~g} \mathrm{~mol}^{-1}$ and a melting point at $33-40{ }^{\circ} \mathrm{C}$, was used as the PEG treatment.

Table 1. Elemental composition of AOD slag $\left(\mathrm{mg} \mathrm{g}^{-1}\right)$

\begin{tabular}{cccccccc}
\hline & $\mathrm{Si}$ & $\mathrm{Mn}$ & $\mathrm{P}$ & $\mathrm{Al}$ & $\mathrm{Ca}$ & $\mathrm{Fe}$ & $\mathrm{Mg}$ \\
\hline $\mathrm{AOD}$ & 150 & 4 & 0.04 & 9 & 380 & 3 & 33 \\
\hline
\end{tabular}

\subsection{PEG1000 modification}

Polyethylene glycol is a water-miscible polyether with varying molecular weight. In this experiment, PEG with a molecular weight of around 1000 was used (PEG1000). Silicates and calcium-rich solids on the slag surface can be transformed to calcium silicate hydrate (CSH) under hydrothermal conditions (Jing et al. 2007, Hosokawa et al. 2014). Guan et al. (2014) reported that the presence of PEG can effectively prevent the aggregation of small $\mathrm{CSH}$ particles during hydrothermal treatment, leading to the formation of CSH with larger surface area. The aim of the modification applied in the present study was to improve the reaction kinetics and the maximum PRC of AOD slag by modifying calcium silicate on the slag surface through hydrothermal treatment with PEG.

The modification process was as follows: a fixed amount of PEG was dissolved in deionised water at a solid:liquid ratio of 1:225 to form a PEG solution, which was stirred for 30 minutes to ensure complete dissolution. Then AOD slag with particle size of 0-0.5 mm (fine fraction) and 0.5-1 mm (coarse fraction) was added to the solution at a PEG:AOD slag mass ratio of 2:5. A control group was prepared by adding the same amount of slag to deionised water. All suspensions were then placed in a water bath for 2 hours at $80{ }^{\circ} \mathrm{C}$ with a 
stirring rate of $60 \mathrm{rpm}$ and later removed to an autoclave for hydrothermal treatment at $120{ }^{\circ} \mathrm{C}$ for 12 hours

(Guan et al. 2013, Guan et al. 2014). The suspension was cooled to room temperature. Centrifugation at 8000 rpm for 3 min was carried out to separate the AOD slag from the PEG solution. The modified AOD slag was dried at $105^{\circ} \mathrm{C}$ and then collected in zip-lock plastic bags and referred to as fAOD-PEG (0-0.5 mm), cAOD-PEG (0.5-1 mm), fAOD and cAOD.

\subsection{Experiment methods}

The PRE of AOD was initially investigated in a series of batch experiments with synthetic P solution. A stock synthetic solution of $1000 \mathrm{mg} \mathrm{P} \mathrm{L}^{-1}$ was prepared by dissolving $\mathrm{KH}_{2} \mathrm{PO}_{4}$ in distilled water. The solution was then stored in a refrigerator at $4{ }^{\circ} \mathrm{C}$. The working $\mathrm{P}$ solution was prepared fresh daily by diluting a defined volume of stock solution with distilled water to an experimental concentration of $6.5 \mathrm{mg} \mathrm{P} \mathrm{L}^{-1}$, which is similar to the $\mathrm{P}$ concentration in real wastewater. A fixed volume of $0.1 \mathrm{~mol} \mathrm{~L}^{-1} \mathrm{NaNO}_{3}$ was then added to the working $\mathrm{P}$ solution to ensure a background of $0.001 \mathrm{~mol} \mathrm{~L}^{-1} \mathrm{NaNO}_{3}$. Finally, the $\mathrm{pH}$ of the working solution was adjusted to 7.0 \pm 0.1 by drop-wise addition of $0.1 \mathrm{~mol} \mathrm{~L}^{-1} \mathrm{NaOH}$.

The wastewater used in this experiment was a septic tank effluent (design flow: $1.6 \mathrm{~m}^{3} \mathrm{~d}^{-1}$ ), which was used without any further treatment except that coarse particles were removed using filter cotton. The wastewater was stored in plastic containers at room temperature for several days. The mean $\mathrm{pH}$ of the wastewater was 7.42 and the P concentration was $8.2 \pm 0.4 \mathrm{mg} \mathrm{L}^{-1}$. 
Triplicate samples of $0.5 \mathrm{~g}$ AOD were suspended in $100 \mathrm{~mL}$ synthetic solution or in real wastewater using a series of plastic bottles. The suspensions were shaken at $50 \mathrm{rpm}$ in an end-over-end shaker at room temperature $\left(22^{\circ} \mathrm{C}\right)$. Supernatant samples were taken from synthetic solutions after the following agitation periods: $0.33,0.66$, 1, 1.5, 2, 2.5, 3.33, 4 and $10 \mathrm{~h}$, and from real wastewater after: 0.17, 0.5, 1, 3, 5, 8, 10, 14, 18,22 and 48 h. Before sampling, the bottles were kept still for 2 minutes to allow particle settling. Immediately after sampling, the $\mathrm{pH}$ value of the samples was measured using a typical combination electrode. Filtration was carried out using a $0.45 \mu \mathrm{m}$ syringe filter to prepare samples for P analysis. The PRE was expressed as a percentage and calculated using the following equation:

$$
\mathrm{PRE}=100 \times\left(\mathrm{P}_{0}-\mathrm{P}\right) / \mathrm{P}_{0}
$$

where $\left(P_{0}-P\right)$ is the difference between the initial $\left(P_{0}\right)$ and measured $(P)$ concentration in the supernatant.

The PRC of AOD was tested under different initial P concentrations on a batch basis. Triplicate samples of 0.5 g AOD slag were suspended in $100 \mathrm{~mL}$ of a synthetic solution with eight different initial P concentrations (6.7, 12, 17.5, 23.3, 30, 60, 105, $308 \mathrm{mg} \mathrm{L}^{-1}$ ). These synthetic solutions were prepared in the same way as in the kinetic experiments. The bottles were shaken at $50 \mathrm{rpm}$ at $22{ }^{\circ} \mathrm{C}$ on an end-over-end shaker for 24 hours and then kept still for another 24 hours before sampling.

The P removal capacity of AOD slag under these different scenarios was calculated using the following equation (Barca et al. 2012):

$$
\mathrm{PRC}=\left(\mathrm{P}_{0}-\mathrm{P}\right) V / m
$$


where $\mathrm{P}_{0}$ is the initial $\mathrm{P}$ concentration of the synthetic solution, $\mathrm{P}$ is the $\mathrm{P}$ concentration of the supernatant sample, $V$ is the volume of the synthetic solution in each bottle, $m$ is the mass of AOD in each bottle and PRC is expressed in $\mathrm{mg} \mathrm{P}^{-1}$.

To determine an optimal AOD slag dose that can ensure satisfactory P removal from a real wastewater, batch experiments were carried out. Triplicate samples of AOD slag were suspended in $100 \mathrm{~mL}$ wastewater. The AOD slag doses used were $0.5,1,1.5,2,2.5$ and $3 \mathrm{~g}$. The suspensions were shaken in an end-over-end shaker for 8 hours, kept still for 2 minutes and then samples were taken for $\mathrm{pH}$ measurement and $\mathrm{P}$ analysis.

To compare the P removal performance of AOD slag before and after PEG modification, triplicate samples of $0.5 \mathrm{~g}$ AOD slag (fAOD, fAOD-PEG, cAOD, cAOD-PEG) were suspended in a series of $100 \mathrm{~mL}$ synthetic $\mathrm{P}$ solutions with an initial P concentration of $20 \mathrm{mg} \mathrm{L}^{-1}$. After a certain period of shaking $(0.33,0.66,1,1.33,1.66$, 2.17, 3, 4, 5.17, 6.5, 8 hours), the supernatant samples were collected for measurement. All these samples were filtered with a $0.45 \mu \mathrm{m}$ syringe filter for $\mathrm{P}$ analysis. Samples for $\mathrm{Ca}^{2+}$ determination were acidified by addition of $3 \% \mathrm{HNO}_{3}$ by volume.

\subsection{Analytical methods}

Analysis of P as phosphate was performed using a Seal Analytical AA3 Autoanalyzer. The instrument was calibrated prior to analysis using working standard solutions in the range 0 to $10 \mathrm{mg} \mathrm{P} \mathrm{L}^{-1}$. The $\mathrm{Ca}^{2+}$ concentration was determined using an inductively coupled plasma optical emission spectrometry (ICP-OES) 
instrument (Thermo Scientific Icap 6000). The pH of all samples was measured using a Hach pH meter (Sension $\left.{ }^{\mathrm{TM}} \mathrm{pH} 31\right)$.

Visual MINTEQ 3.1 (Gustafsson 2014) was used to calculate the saturation index of different Ca-P minerals that could form in this experiment, using the default equilibrium constants of complexes and precipitates in the Visual MINTEQ database. Calculated ion activity products (IAP) were compared against solubility constants to cast light on the P removal mechanism of AOD. The solubility constants for different calcium phosphates were taken from Gustafsson et al. (2008), see Table 2.

Table 2 - Solubility constants and heats of reaction for Ca phosphates used in Visual MINTEQ

\begin{tabular}{lcc}
\hline Reaction & $\log K_{s}\left(25^{\circ} \mathrm{C}\right)^{\mathrm{a}}$ & $\Delta H_{r}(\mathrm{~kJ} / \mathrm{mol})^{\mathrm{a}}$ \\
\hline Hydroxyapatite: $\mathrm{Ca}_{5}\left(\mathrm{PO}_{4}\right)_{3} \mathrm{OH}(\mathrm{s})+\mathrm{H}^{+} \Leftrightarrow 5 \mathrm{Ca}^{2+}+3 \mathrm{PO}_{4}{ }^{3-}+\mathrm{H}_{2} \mathrm{O}$ & $-44.3^{\mathrm{b}}$ & 0 \\
OCP: $\mathrm{Ca} 4 \mathrm{H}\left(\mathrm{PO}_{4}\right)_{3}(\mathrm{~s}) \Leftrightarrow 4 \mathrm{Ca}^{2+}+3 \mathrm{PO}_{4}{ }^{3-}+\mathrm{H}^{+}$ & $-47.95^{\mathrm{c}}$ & $-105^{\mathrm{c}}$ \\
Monetite: $\mathrm{CaHPO}_{4}(\mathrm{~s}) \Leftrightarrow \mathrm{Ca}^{2+}+\mathrm{PO}_{4}{ }^{3-}+\mathrm{H}^{+}$ & -19.28 & 31 \\
Brushite: $\mathrm{CaHPO}_{4} \times 2 \mathrm{H}_{2} \mathrm{O}(\mathrm{s}) \Leftrightarrow \mathrm{Ca}^{2+}+\mathrm{PO}_{4}{ }^{3-}+\mathrm{H}^{+}+2 \mathrm{H}_{2} \mathrm{O}$ & -19.00 & 23 \\
ACP2: $\mathrm{Ca}_{3}\left(\mathrm{PO}_{4}\right)_{2}(\mathrm{~s}) \Leftrightarrow 3 \mathrm{Ca}^{2+}+2 \mathrm{PO}_{4}{ }^{3-}$ & $-28.25^{\mathrm{c}}$ & $-87^{\mathrm{c}}$ \\
ACP1: $\mathrm{Ca}_{3}\left(\mathrm{PO}_{4}\right)_{2}(\mathrm{~s}) \Leftrightarrow 3 \mathrm{Ca}^{2+}+2 \mathrm{PO}_{4}{ }^{3-}$ & $-25.5^{\mathrm{c}}$ & $-94^{\mathrm{c}}$ \\
\hline
\end{tabular}

${ }^{\mathrm{a}}$ Unless otherwise stated, the values are from Smith et al. (2003).

${ }^{\text {b}}$ Solubility of hydroxyapatite at $21^{\circ} \mathrm{C}$ (McDowell et al. 1977).

${ }^{\mathrm{c} C a l c u l a t e d ~ f r o m ~ r a w ~ d a t a ~ g i v e n ~ b y ~ C h r i s t o f f e r s e n ~ e t ~ a l . ~(1990) ~}$

Two batches of used AOD slag were collected and labelled AOD-20 and AOD-300, as the initial P concentration of the suspension was around 20 (23.3) and 300 (308) $\mathrm{mg} \mathrm{P} \mathrm{L}^{-1}$, respectively. The used slag was collected by filtering the suspension through a $1 \mathrm{~mm}$ sieve and it was then washed three times with deionised water. White precipitates from the experiment with initial $\mathrm{P}$ concentration of $23.3 \mathrm{mg} \mathrm{P} \mathrm{L}{ }^{-1}$ were collected by centrifuging the filtrate at $8000 \mathrm{rpm}$ for $5 \mathrm{~min}$ and labelled WP. Used fAOD-PEG slag suspended in $20 \mathrm{mg} \mathrm{P} \mathrm{L}^{-1}$ synthetic 
solution was separated from the suspension by carefully removing the supernatant and visible white precipitates and then rinsed three times with deionised water. This solid sample was named AOD-P, as it was P precipitated, PEG-adjusted AOD slag. All four samples were placed in a fume hood overnight for dewatering at room temperature. No further pretreatment other than gentle grinding in a mortar was conducted prior to XANES analysis

Speciation of the Ca- $\mathrm{PO}_{4}$ precipitates in the four solid samples (S1-4) was performed using XANES spectroscopy. The samples were ground in a mineral grinder, mounted on Kapton tape and then analysed using P K-edge XANES spectroscopy on beamline BL8 of the Synchrotron Light Research Institute, Thailand (Klysubun et al. 2012). The beamline was operated in fluorescence mode and the fluorescence signal was measured using a solid state 13-channel Ge detector. The beam current ranged from 80 to $150 \mathrm{~mA}$. An InSb (111) double crystal monochromator with an energy resolution $(\Delta \mathrm{E} / \mathrm{E})$ of $3 \times 10^{-4}$ and a dwell time of $3 \mathrm{~s}$ was used. To minimise $\mathrm{X}$ ray absorption by air, the sample compartment was filled with helium gas. The scans ranged from 2100 to 2320 $\mathrm{eV}$, with a smaller energy step near the absorption edge (down to $0.2 \mathrm{eV}$ between 2144-2153 eV). Between 3 and 7 scans per sample were collected, depending on the level of noise in the data, and subsequently merged.

The XANES data were processed using the Athena program in the Demeter Software Package (v 0.9.20) (Ravel and Newville 2005). The energy was established by setting the maximum of the first derivative of the spectrum for elemental P powder (E0) to $2146 \mathrm{eV}( \pm 0.11 \mathrm{eV}$ ). Correction of any shifts on the energy scale caused by monochromator drift could be performed since validation data for variscite were collected periodically. Merged spectra were normalised using a consistent procedure. A linear baseline function was subtracted from 
the spectral region below the edge (between -30 to $-10 \mathrm{eV}$ relative to E0), and spectra were normalised to a unit edge step and quadrature removed across the post-white-line region (between 30 and $50 \mathrm{eV}$ relative to E0) to obtain normalised XANES spectra.

Using a linear combination fitting (LCF) approach (Tannazi and Bunker 2005), a set of spectra of known standards were combined and fitted to the sample spectra. All standards used in the evaluation had been confirmed previously by X-ray powder diffraction, while XANES data were collected at the same beamline as the samples. The standard compounds included amorphous calcium phosphate (ACP), octacalcium phosphate (OCP), natural apatite (HAP), brushite (DCPD), monetite (DCP), amorphous aluminium phosphate, phosphate adsorbed to aluminium hydroxide, phosphate adsorbed to gibbsite, variscite, amorphous iron phosphate, phosphate adsorbed to ferrihydrite, phosphate adsorbed to goethite, strengite, struvite, lecithin and phytate. In the fitting procedure, no energy shifts were permitted and the sum of the weighting factors was not forced to one. At most three standards were accepted in each fit and the fitting range was constrained to between -10 to $30 \mathrm{eV}$ relative to E0.

\section{Results and discussion}

\subsection{Kinetics of $P$ removal from synthetic solutions}

In general, AOD slag removed P efficiently from the synthetic solution, with $50.6 \%$ of the P removed in the first 1.5 h. The PRE then continued to increase to $94.8 \%$ after $4 \mathrm{~h}$ and to $97.5 \%$ after $10 \mathrm{~h}$ (Fig. 1a). The initial P concentration was $6.5 \mathrm{mg} \mathrm{L}^{-1}$ and the final P concentration of the solution was $0.16 \mathrm{mg} \mathrm{L}^{-1}$, giving a PRC of 1.27 mg P g ${ }^{-1}$. Compared with EAF slag and BOF slag, with P removal efficiencies less than $90 \%$ after 7 days of 
contact (Barca et al. 2012), AOD slag demonstrated better P removal performance in a much shorter time. The $\mathrm{pH}$ of the supernatant increased from 7 at the beginning of the experiment to 10.03 after $1 \mathrm{~h}$ and then rose slowly to 11.06 after $10 \mathrm{~h}$.

The results of the kinetics study with real wastewater are presented in Fig. 1b. The initial P concentration of the wastewater was $8.65 \mathrm{mg} \mathrm{P} \mathrm{L} \mathrm{L}^{-1}$ and the $\mathrm{pH}$ was 7.42 . After $22 \mathrm{~h}$ of agitation the $\mathrm{P}$ concentration dropped to $1.36 \mathrm{mg} \mathrm{L}^{-1}$, while the $\mathrm{pH}$ increased to 9.05. During this period the AOD slag achieved a PRE of 82.7\%, giving a PRC of $1.46 \mathrm{mg} \mathrm{P} \mathrm{g}^{-1}$. After $48 \mathrm{~h}$ of reaction, the $\mathrm{P}$ concentration of wastewater decreased to $1.02 \mathrm{mg} \mathrm{L}^{-1}$ and the PRE increased slightly to $88.16 \%$, while the $\mathrm{pH}$ decreased from 9.05 to 8.91 . Thus the AOD slag reached a PRC of $1.54 \mathrm{mg} \mathrm{P} \mathrm{g}^{-1}$. In Sweden, the effluent $\mathrm{P}$ discharge standard for onsite wastewater treatment is $1 \mathrm{mg} \mathrm{L}^{-1}$ or less than $10 \%$ of $\mathrm{P}$ in the influent, which was met in this experiment. The above results therefore confirmed that AOD slag is an effective P removal material.

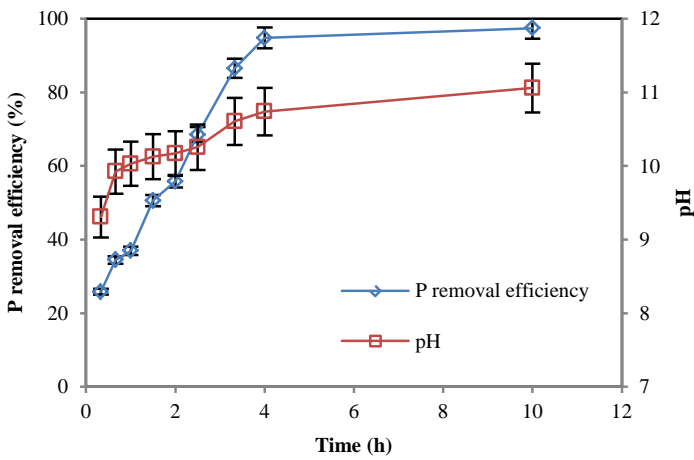

a)

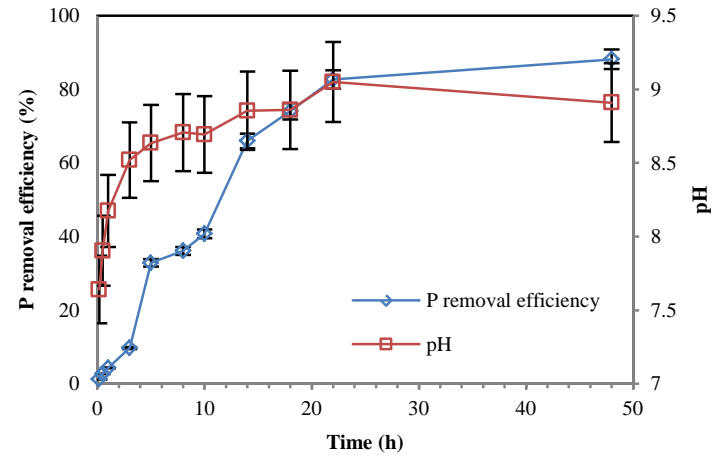

b)

Fig. 1. Kinetics of $\mathbf{P}$ removal and $\mathrm{pH}$ change in (a) the synthetic solution and (b) real wastewater.

The trends of increasing $\mathrm{pH}$ and decreasing $\mathrm{P}$ were similar in both systems, but the progression with real wastewater was slower than that with synthetic P solution. It has been demonstrated that dissolved organic 
matter in wastewater can interfere with $\mathrm{P}$ removal by BF slag and therefore extensive pre-treatment of wastewater is essential to achieve satisfactory P removal (Nilsson et al. 2013). The real wastewater used in this

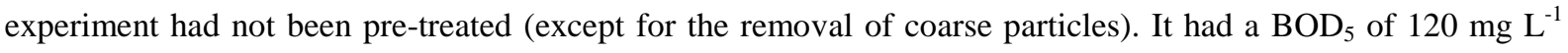
and a total inorganic nitrogen content of $78.82 \mathrm{mg} \mathrm{L}^{-1}$. Therefore it seems likely that the $\mathrm{P}$ removal rate was slowed down by the presence of organic matter in the wastewater.

Organic acids and $\mathrm{CO}_{2}$ generated from biological degradation and inorganic $\mathrm{NH}_{4}^{+}$may exert a buffering effect on pH (Hendon 2014, Van Vooren et al. 1999, Chen et al. 2004). As shown in Fig. 1b, although the contact time with wastewater was longer, the $\mathrm{pH}$ increase in real wastewater (from 7.42 to 8.91) was lower than in the synthetic solution (from 7 to 11.06). The $\mathrm{P}$ speciation in solution is dependent on the $\mathrm{pH}$, since at higher $\mathrm{pH}$ an increased proportion of $\mathrm{P}$ exists as $\mathrm{PO}_{4}{ }^{3-}$ ions, which together with $\mathrm{Ca}^{2+}$ may form precipitates such as apatite and amorphous calcium phosphate (Gustafsson et al. 2008). Thus, a lower pH may lead to less efficient P removal.

A possible reason for the quick increase in $\mathrm{P}$ removal and $\mathrm{pH}$ in the first 40 minutes in both the synthetic solution and real wastewater is rapid precipitation of phosphate (Table 2) with $\mathrm{Ca}^{2+}$ that originates from the dissolution of calcium-rich silicates on the surface of the slag. Although the chemical composition of AOD slag is variable, the main minerals present are dicalcium silicate $\left(\gamma-\mathrm{C}_{2} \mathrm{~S}, \mathrm{Ca}_{2} \mathrm{SiO}_{4}\right)$, merwinite $\left(\mathrm{Ca}_{3} \mathrm{Mg}(\mathrm{SiO})_{2}\right)$ and bredigite $\left(\mathrm{Ca}_{14} \mathrm{Mg}_{2}\left(\mathrm{SiO}_{4}\right)_{8}\right)$ (Shen and Forssberg 2003, Kriskova et al. 2012, Santos et al. 2013a, Santos et al. 2013b). These minerals dissolve according to the following equation (Wouter et al. 2006):

$$
\text { Ca-silicate(s) }+2 \mathrm{H}^{+}(\mathrm{aq}) \rightarrow \mathrm{Ca}^{2+}(\mathrm{aq})+\operatorname{silicate}(\mathrm{s})+\mathrm{H}_{2} \mathrm{O}(\mathrm{l})
$$


This reaction provides the $\mathrm{Ca}^{2+}$ needed for $\mathrm{Ca}-\mathrm{PO}_{4}$ precipitation and consumes $\mathrm{H}^{+}$, leading to $\mathrm{P}$ removal and to the $\mathrm{pH}$ increase in solution. Thus it can be considered a crucial step in the Ca- $\mathrm{PO}_{4}$ precipitation process. After 40 minutes, both the $\mathrm{P}$ removal and the $\mathrm{pH}$ increase slowed down, possibly because accumulation of $\mathrm{Ca}-\mathrm{PO}_{4}$ precipitates, residual silica and unreactive minerals restricted the diffusion of calcium through the solid slag matrix towards the slag surface, and thus limited the contact between the unreacted inner part of the AOD slag and phosphate in the aqueous medium.

\subsection{Effect of initial phosphate concentration}

The results of the experiments with varying initial P concentrations are shown in Fig. 2. The P removal of AOD slag was proportional to the increase in initial P concentration, while the PRE decreased. The highest PRC value, 27.47 $\mathrm{mg} \mathrm{P} \mathrm{g}^{-1}$, was observed when the initial $\mathrm{PO}_{4}-\mathrm{P}$ concentration was $308 \mathrm{mg} \mathrm{L}^{-1}$. At the same time the PRE was only 44.6\%. However, in solutions with initial P concentrations between 6.7 to $30 \mathrm{mg} \mathrm{P} \mathrm{L}^{-1}$, PRE values above 97.5\% were achieved and a rapid linear increase in PRC was also observed in this region. With the initial P concentration increasing from $60 \mathrm{mg} \mathrm{L}^{-1}$ to $308 \mathrm{mg} \mathrm{L}^{-1}$, the PRE decreased from $80.4 \%$ to $44.6 \%$ and the PRC increased from 5.95 to $27.47 \mathrm{mg} \mathrm{P} \mathrm{g}^{-1}$. One possible reason for the decreased PRE was the limited availability of $\mathrm{Ca}^{2+}$ in the suspension, as shown in Fig. 2b. The final $\mathrm{Ca}^{2+}$ concentration decreased from 99 to $44 \mathrm{mg} \mathrm{L}^{-1}$ as the initial P concentration increased from 6.7 to $30 \mathrm{mg} \mathrm{L}^{-1}$. The main reason was probably the dramatic decrease in $\mathrm{pH}$ in the solutions, as shown in Fig. 2, which meant that a higher concentration of $\mathrm{PO}_{4}{ }^{3-}$ was present at equilibrium and consequently that precipitation was less efficient. 


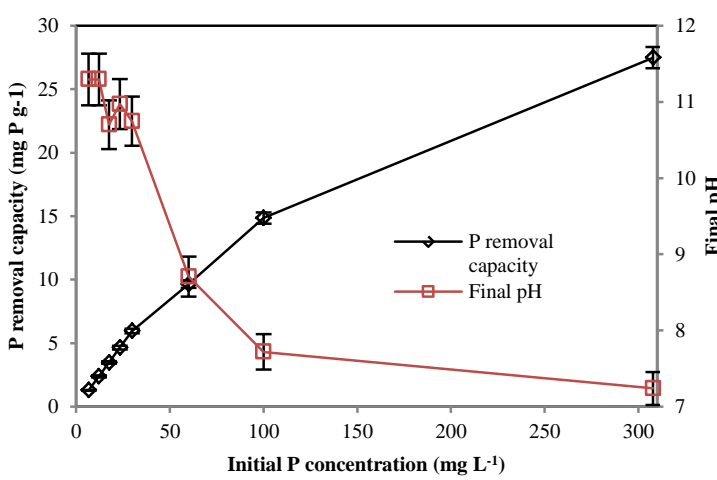

a)

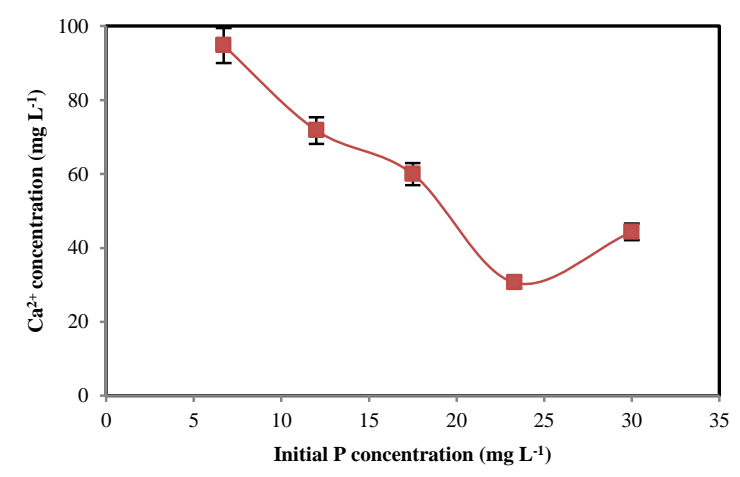

b)

Fig. 2. Effect of initial $P$ concentration on $P$ removal capacity.

Barca et al. (2012) investigated P removal by EAF and BOF slags from solutions containing $100 \mathrm{mg} \mathrm{P} \mathrm{L}^{-1}$ and found that the highest PRC achieved was $2.49 \mathrm{mg} \mathrm{P} \mathrm{g}^{-1}$, much lower than that of AOD slag (14.86 $\left.\mathrm{mg} \mathrm{P} \mathrm{g}^{-1}\right)$ for a similar solution in the present study. One reason might be that the content of readily soluble $\mathrm{CaO}$ and $\mathrm{Ca}$ silicates is higher in AOD slag (380 $\left.\mathrm{mg} \mathrm{g}^{-1}\right)$ than in EAF slag (170 mg g $\mathrm{g}^{-1}$ ) and BOF slag (377 mg g $\mathrm{g}^{-1}$ ). Another probable reason is that the particle size of the AOD slag $(1-2 \mathrm{~mm})$ in this study was smaller than that of the slags (5-10 mm) studied by Barca et al. (2012), leading to more efficient dissolution because of a larger wetted surface area.

Visible white precipitates were observed in all solutions 20 minutes after the experiments started. Higher initial P concentration resulted in an increased amount of white precipitates on the surface of the AOD slag and in the solution, which also partly confirms that precipitation was one of the main mechanisms for $\mathrm{P}$ removal. No tendency for clogging and slag aggregation was observed in solutions with initial P concentration lower than 100 mg P L ${ }^{-1}$. However, with initial $\mathrm{P}$ concentrations higher than $100 \mathrm{mg} \mathrm{P} \mathrm{L}^{-1}$, the separated slag particles tended to clump together and aggregate into larger particles, but the occurrence of such a high $\mathrm{P}$ concentration in 
wastewater is very unlikely, so the possibility of chemical clogging and hydraulic failure can probably be ignored.

Structural disintegration of the solid matrix could have been expected because of its chemical composition and the extended shaking time, but this was not observed. Several studies have demonstrated that the free lime in slag reacts with water to form hydroxides, causing a volume increase accompanied by disintegration of the slag (Motz et al. 2001, Engström et al. 2014). In this study, the free lime and soluble calcium silicate dissolved from the slag and were partly re-precipitated with phosphate in the aqueous phase, which prevented volume increase and disintegration. This is a very attractive characteristic from a practical application point of view.

\subsection{Effect of AOD dose on P removal from wastewater}

The PRE of AOD as a function of dose is presented in Fig. 3. The P removal was accelerated by increasing the AOD dose. The kinetics study showed that $88 \%$ of $\mathrm{P}$ was removed from the wastewater with a contact time of 22 hours by 0.5 g AOD slag. However, a PRE of 90.6\% (>90\%, the effluent P discharge standard) with a contact time of 8 hours was achieved by raising the dose to $25 \mathrm{~g} \mathrm{~L}^{-1}$.

When the AOD dosage was increased from 5 to $10 \mathrm{~g} \mathrm{~L}^{-1}$ the corresponding PRE almost doubled, i.e. it increased from $36.1 \%$ to $71.9 \%$, which might have resulted from an increase in available $\mathrm{Ca}^{2+}$ in the aqueous medium. This is probably because the wetted surface area doubled, leading to enhanced dissolution of Ca silicates. This interpretation was also supported by the observed increase in $\mathrm{pH}$ from 8.8 to 9.0. 


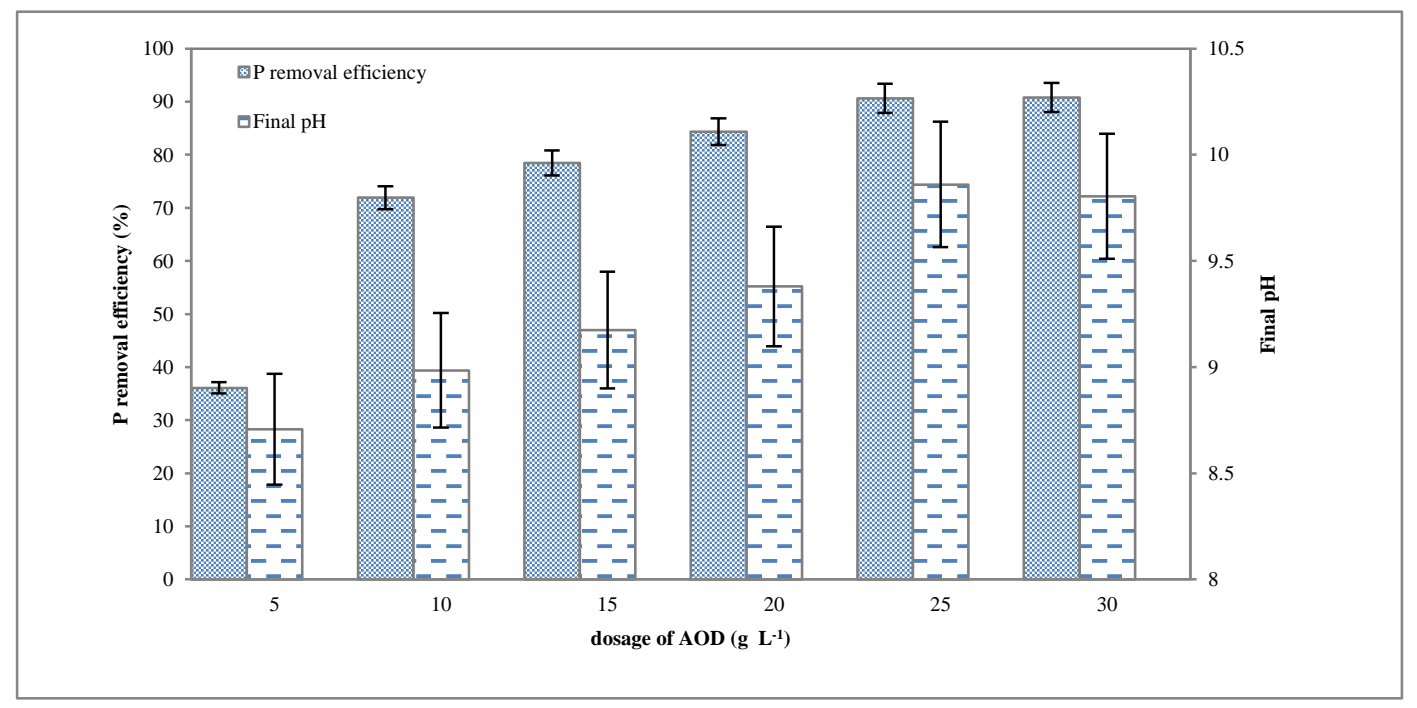

Fig. 3. Effect of AOD dose on P removal from wastewater.

For doses ranging from 10 to $25 \mathrm{~g} \mathrm{~L}^{-1}$, an almost equal increase (6\%) in PRE was observed between each two adjacent dosages, as PRE was 71.9\%, 78.5\%, 84.3\% and 90.6\%, respectively. Song et al. (2002) investigated the effects of solution conditions on the precipitation of calcium phosphates and found the saturation index with respect to hydroxyapatite to be a logarithmic function of the phosphate concentration and the calcium concentration. With the increase in $\mathrm{Ca}^{2+}$ concentration and $\mathrm{pH}$ in the supernatant due to the increasing dose in the present study, the saturation index also increased, leading to further precipitation of calcium phosphate.

Increasing the dose to $30 \mathrm{~g} \mathrm{~L}^{-1}$ appeared to have a very weak influence, because the PRE (90.8\%) was just slightly higher than that obtained at $25 \mathrm{~g} \mathrm{~L}^{-1}$ (90.6\%). The $\mathrm{pH}$ for the $30 \mathrm{~g} \mathrm{~L}^{-1}$ dose was even slightly lower than for $25 \mathrm{~g} \mathrm{~L}^{-1}$. Based on previous research (Song et al. 2002, Ali et al. 2006), it is reasonable to assume that critical supersaturation with respect to calcium phosphate occurred in the supernatants with these two doses, where the addition of suitable seed materials instead of an increase in $\mathrm{Ca}^{2+}$ concentration would be needed for complete $\mathrm{P}$ removal from the wastewater. Therefore further increasing the dose did not greatly improve the PRE, so the recommended AOD slag dosage for P removal from wastewater in batch-operated systems would be $25 \mathrm{~g} \mathrm{~L}^{-1}$. 


\subsection{Effect of PEG1000}

The PRC for all four AOD samples is shown in Fig. 4. The fAOD-PEG sample had the highest PRC (2.16 mg P $\left.\mathrm{g}^{-1}\right)$, followed by fAOD (1.46 $\left.\mathrm{mg} \mathrm{P}^{-1}\right)$, cAOD-PEG $\left(0.97 \mathrm{mg} \mathrm{P} \mathrm{g}^{-1}\right)$ and cAOD $\left(0.9 \mathrm{mg} \mathrm{P} \mathrm{g}^{-1}\right)$. The fAOD-PEG removed more than twice as much $\mathrm{P}$ as the cAOD-PEG $\left(0.97 \mathrm{mg} \mathrm{P}^{-1}\right)$. It is noticeable that the difference in $\mathrm{P}$ removal between fAOD-PEG and fAOD $\left(0.7 \mathrm{mg} \mathrm{P} \mathrm{g}^{-1}\right)$ was 10 -fold greater than that between cAOD-PEG and cAOD $\left(0.07 \mathrm{mg} \mathrm{P} \mathrm{g}^{-1}\right)$. The greater P removal difference among the finer group indicates that larger contact area between the treated AOD slag and the PEG solution intensified the effect of PEG treatment in improving P removal performance.

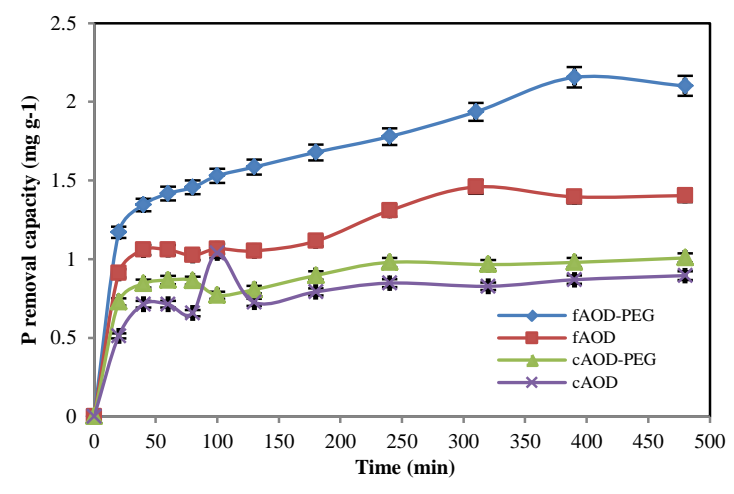

a)

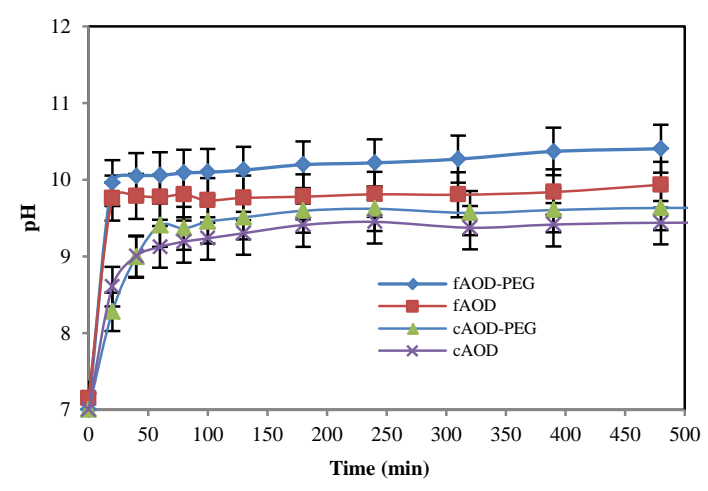

b)

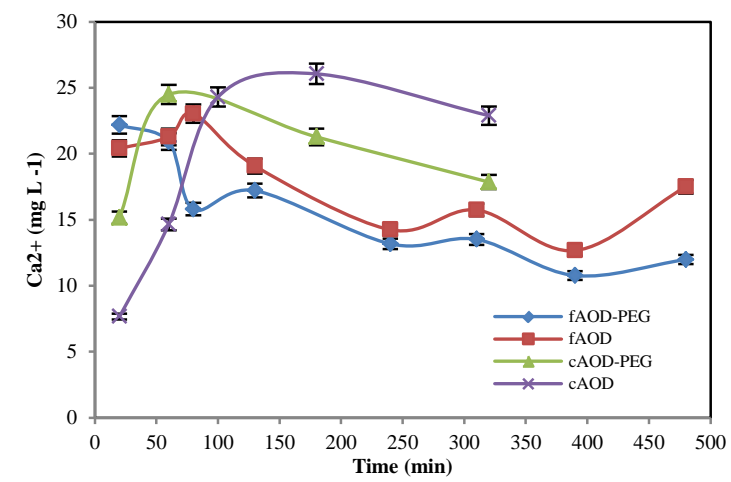

c)

Fig. 4. Effect of PEG on (a) $\mathrm{P}$ removal capacity, (b) $\mathrm{pH}$ and (c) $\mathrm{Ca}^{2+}$ change in the solution. 
The cAOD and cAOD-PEG almost stopped removing P after 1 hour, earlier than fAOD and fAOD-PEG, in which P removal continued at a slower rate and stopped at 390 min. The prolonged P removal by fAOD and fAOD-PEG was probably attributable to the higher $\mathrm{pH}$, although the available $\mathrm{Ca}^{2+}$ concentration in the aqueous medium of both these samples was lower than in the medium of the other two types (Fig. 4c).

The calcium release was quicker for PEG-treated AOD slag at the beginning of the experiment, resulting in higher P removal in the first 40 minutes, as shown in Fig. 4a \& c, which meant that the dissolution of calcium silicates was faster from PEG-treated slags. Therefore PEG seemed to enhance the solubility of calcium silicates, as reported previously (Guan et al. 2013, Guan et al. 2014). The increase in $\mathrm{Ca}^{2+}$ concentrations in all suspensions was accompanied by an increase in $\mathrm{pH}$ and in $\mathrm{P}$ removal at the beginning of the experiment. The fact that fAOD-PEG had a higher $\mathrm{pH}$ than fAOD underlines that PEG contributed to the dissolution of alkaline Ca compounds ( $\mathrm{CaO}$ and $\mathrm{Ca}$ silicates) from the modified slag. For the solutions with cAOD-PEG and cAOD, it was also found that the decrease in $\mathrm{Ca}^{2+}$ concentration was greater than that in $\mathrm{PO}_{4}{ }^{3-}$ concentration, indicating precipitation of $\mathrm{Ca}^{2+}$ with other anions, such as carbonate.

White precipitates were observed in the solution 20 minutes after the experiment started and increased over time, but their particle size did not increase. At the end of the experiment, all AOD samples were whiter than before. Small white precipitates were observed on the surface of all used samples after drying at room temperature. 


\subsection{Visual MINTEQ and XANES analysis}

The output of Visual MINTEQ showed that HAP, OCP and ACP were all supersaturated (Fig. 5), i.e. that they might form in the suspensions. All supernatant samples were undersaturated with respect to brushite and monetite which indicates that these two species can scarcely be formed and they can be ruled out as likely candidates for Ca-P precipitation. These observations agree with those of Gustafsson et al. (2008) for another group of used filter media. The presence of ACP in such materials has been confirmed in XANES studies (Eveborn et al. 2009), but due to the similar XANES spectra of OCP and HAP, this technique could not be used to differentiate between the two.

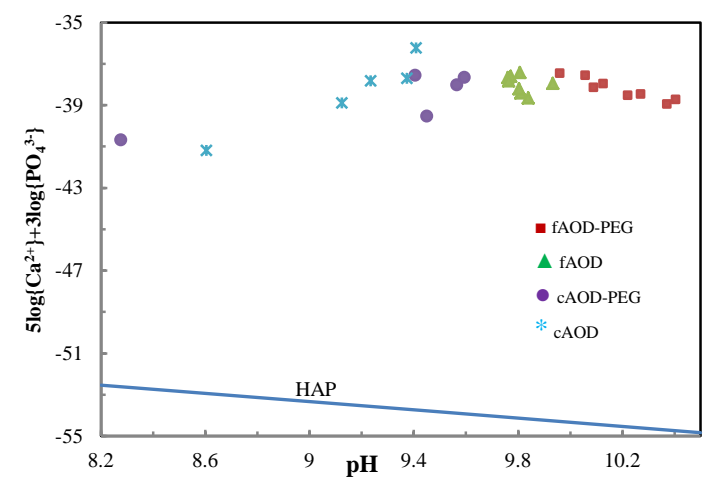

a)

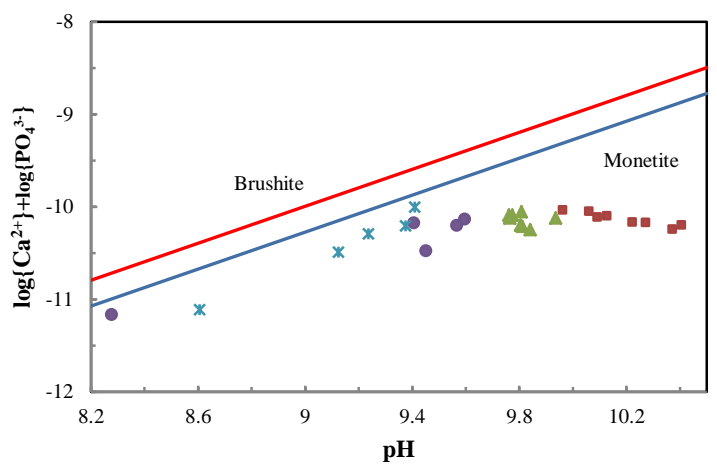

c)

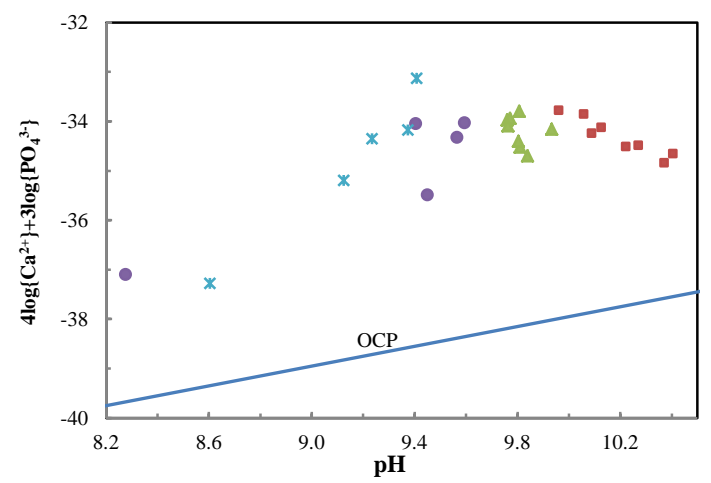

b)

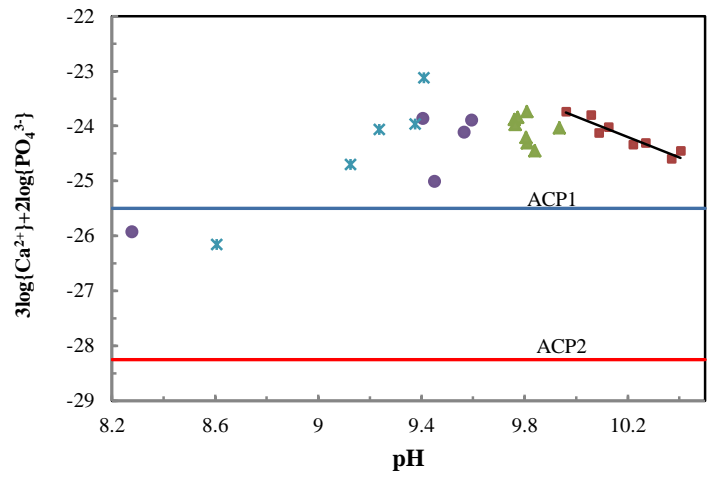

d)

Fig. 5. Plots of $\mathrm{pH}$ vs ionic activity products. The points represent the calculated ionic activity products in the batch experiment. The solid lines are calculated from the solubility parameters of the $\mathrm{Ca}_{-} \mathrm{PO}_{4}$ phases. 
In the supernatant of the fAOD-PEG sample, an almost linear decrease in ionic activity product (IAP) with respect to ACP was observed, which suggested precipitation of ACP over time. For the fAOD supernatant, the decrease in IAP was steeper, indicating that equilibrium could be reached sooner than for fAOD-PEG. This is in agreement with the results in Fig. 4a, which indicated that all suspensions were still supersaturated with respect to ACP even at the end of the experiment. This meant that ACP could be further precipitated as time went by. However, the P removal process became slower as the IAP decreased over time.

\subsection{XANES analysis}

Stacked spectra of the four solid samples and of the standards of relevance to the results are shown in Fig. 6. The Ca phosphate standards showed features similar to those described by Prietzel et al. (2013) and Oxmann (2014).

All Ca phosphates except monetite displayed post-edge shoulders near $2157.5 \mathrm{eV}$, although the shoulders differed in shape depending on the Ca phosphate. The white line is the sharp peak in the rising part of the spectrum and is caused by strong absorption (Bare 2005). Most crystalline Ca phosphates had a post-white line peak at $2164.7 \mathrm{eV}$, which was most strongly pronounced for apatite. For brushite, however, this peak was at slightly lower energy (i.e. at $2164.1 \mathrm{eV}$ ). For ACP this peak was only very weak, in agreement with Eveborn et al. (2009) and Oxmann (2014). Generally, phosphate bound to iron (III) and aluminium (hydr)oxides has strong white lines. Phosphate bound to ferrihydrite and goethite has a characteristic pre-edge (barely visible in Fig. 6), whereas phosphate bound to aluminium hydroxide and gibbsite has a characteristic post-edge feature at around $2160 \mathrm{eV}$. 


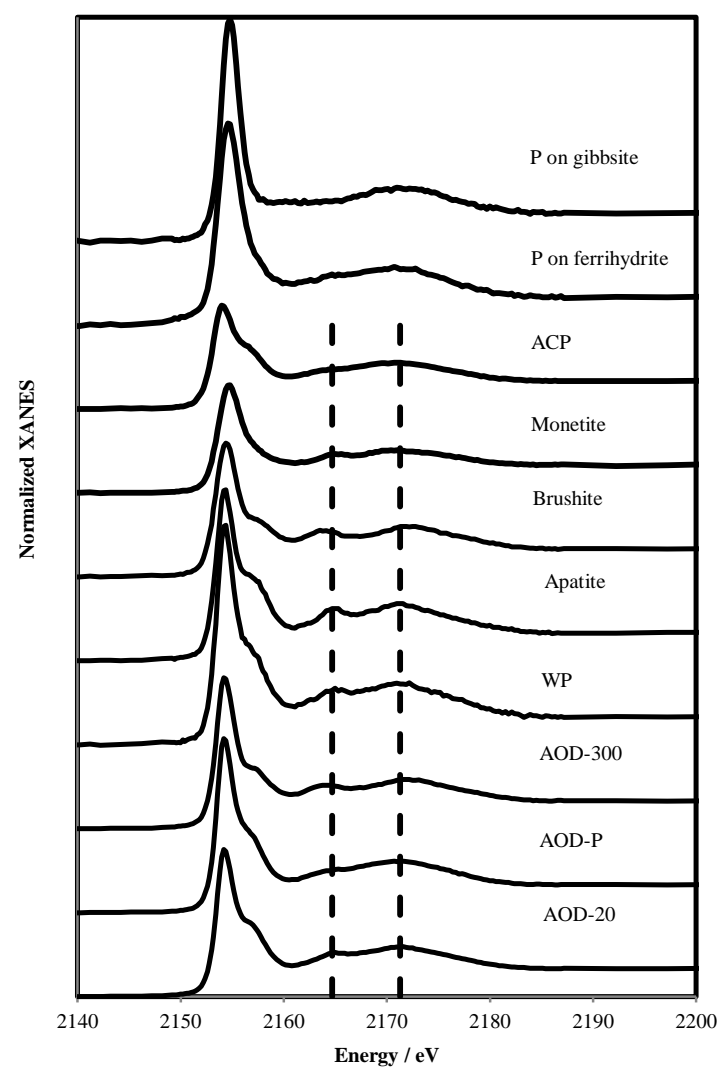

Fig.6. Normalized stacked P K-edge XANES spectra for samples and for the standards of importance in LCF fitting. The dashed lines show the post-white line peaks of apatite at 2164.7 and $2171.3 \mathrm{eV}$.

All four samples were dominated by Ca phosphate mineral phases and the composition of Ca mineral phases was slightly different between the samples. This was clearly apparent both in visual inspection of the stacked spectra (Fig. 6) and from the linear combination fitting results (Fig. 7 and Table 3).

AOD-20 showed post-edge features similar to those of apatite (Fig. 6). According to the LCF results, this sample contained 74\% apatite and minor amounts of monetite and ACP. The final $\mathrm{pH}$ of the solution with AOD-

20 was above 10, which indicated that apatite could be formed in greater proportions in more alkaline solutions.

The WP had apatite-like features in the post-edge region, although slightly less pronounced. According to the LCF results, 73\% of the P was apatite, with the rest being phosphate adsorbed to iron (hydr)oxides (ferrihydrite 
in the best fit). Since this sample was collected from the same aqueous solution as AOD-20, the main P species in the two samples was expected to be the same. However, the contribution of iron (hydr)oxide-bound P in WP was unexpected. It could possibly occur because of P binding to iron oxides on the surfaces of the tiny particles generated from structural disintegration of the slag matrix.

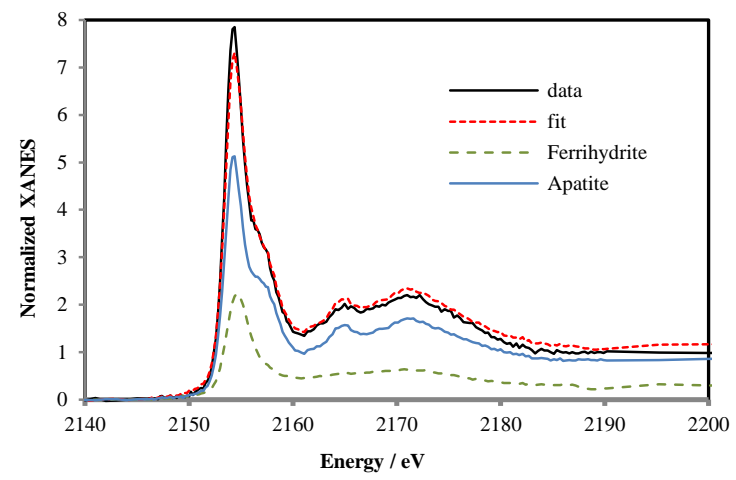

(a)

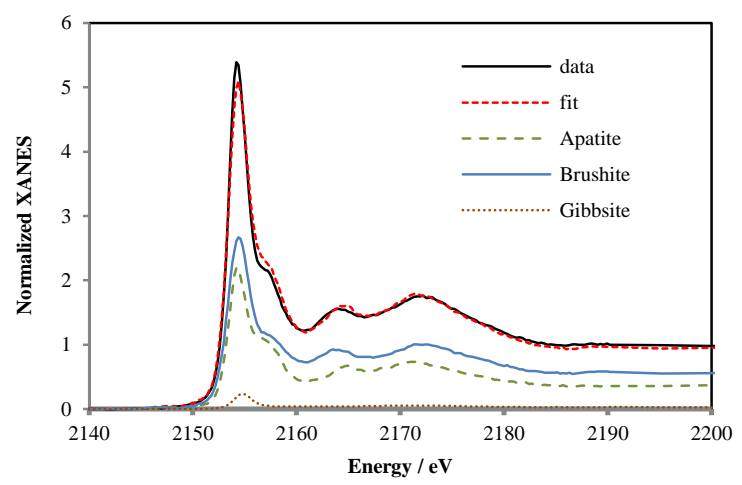

(c)

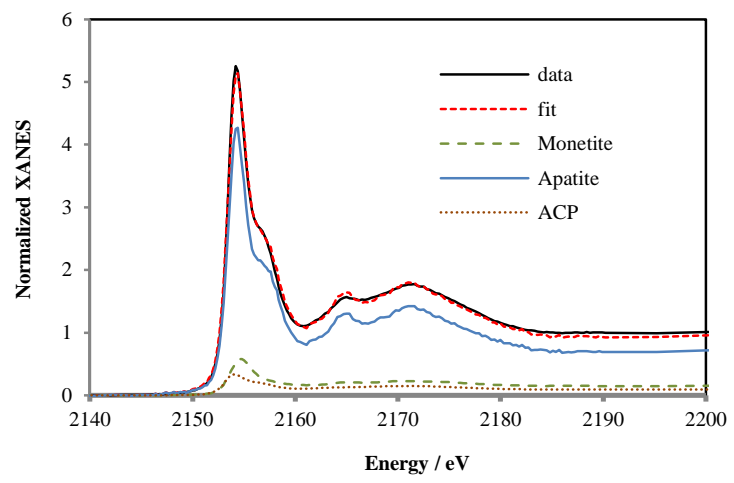

(b)

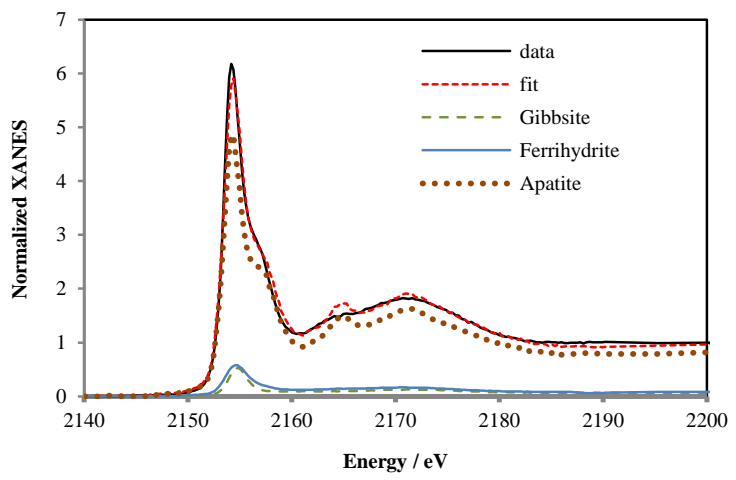

(d)

Fig. 7. Linear combinations and normalized sample data for a) WP, b) AOD-20, c) AOD-300, and d) AOD-P.

Table 3. Phosphorus speciation as evidenced from linear combination fitting of XANES spectra.

\begin{tabular}{|c|c|c|c|c|c|c|c|c|c|}
\hline & & Apatite & OCP & Monetite & Brushite & ACP & $\begin{array}{c}\mathrm{P} \text { on } \mathrm{Al} \\
\text { (hydr)oxideS }\end{array}$ & $\begin{array}{c}\text { P on Fe } \\
\text { (hydr)oxides }\end{array}$ & R-factor ${ }^{a}$ \\
\hline \multirow[t]{2}{*}{ AOD-20 } & weight (\%) & $74 \pm 2 \%$ & & $16 \pm 2 \%$ & & $10 \pm 2 \%$ & & & 0.003 \\
\hline & Presence & $1,2,3,4,5$ & 5 & 1,5 & & $1,2,3,4$ & 2,4 & 3 & \\
\hline \multirow[t]{2}{*}{ AOD-P ${ }^{c}$} & weight (\%) & $84 \pm 4 \%$ & & & & & $7 \pm 4 \%$ & $9 \pm 6 \%$ & 0.008 \\
\hline & Presence & $1,2,3,4,5$ & & & & & $1,2,3,4,5$ & 1 & \\
\hline \multirow[t]{2}{*}{ AOD-300 } & weight (\%) & $38 \pm 4 \%$ & & & $59 \pm 4 \%$ & & $3 \pm 1 \%$ & & 0.008 \\
\hline & Presence & $1,2,3,4,5$ & & & $1,2,3,4,5$ & & 1,3 & 2,4 & \\
\hline \multirow[t]{2}{*}{ WP } & weight (\%) & $73 \pm 3 \%$ & & & & & & $27 \pm 3 \%$ & 0.010 \\
\hline & presence & $1,2,3,4,5$ & & & & & & $1,2,3,4,5$ & \\
\hline
\end{tabular}

The five best fits are numbered from 1 to 5 in italics. $\quad{ }^{a}$ R-factor calculated according to Ravel (2009). 
For AOD-P, the post-edge features were clearly different from those for apatite. The first post-white line peak at $2164.7 \mathrm{eV}$ was only very weak. Despite this, the LCF results indicated dominance of apatite (Table 3). However, from visual inspection of the fit (Fig. 7), it became clear that the post-edge features were not well described by LCF. In fact, the post-white line peaks were weaker, indicating that the Ca phosphates are more amorphous than apatite. The results from Visual MINTEQ also suggested a high possibility of precipitation of ACP, as a linear decrease in the ionic activity product of ACP was observed (Fig. 5d). The reason why ACP was not included in the fit was because the white line intensity of the sample was much stronger than for ACP. In conclusion, this sample probably mainly contained some type of amorphous Ca phosphate not covered by the mineral standards used, based on the fact that the sample was modified with PEG.

AOD-300 showed a strong first post-white line peak. However, visual inspection of Fig. 6 showed that it occurred at slightly lower energy than for apatite and was more in agreement with brushite. This was confirmed by the LCF results showing $59 \%$ of the P to be present as brushite, whereas $38 \%$ was present as apatite. As the final $\mathrm{pH}$ of the solution with AOD-300 was 7.2, it can be concluded that the formation of brushite is favoured by the final $\mathrm{pH}$ in the solution being less than 8 , which is consistent with previous findings (Beauchemin et al. 2003).

In summary, the main P removal mechanism of AOD was precipitation of calcium phosphate. The species of the $\mathrm{P}$ precipitate formed depended on the $\mathrm{pH}$ value and the $\mathrm{Ca}^{2+}$ concentration of the solution. High $\mathrm{pH}$ and $\mathrm{Ca}^{2+}$ concentration, which occurred in most of the suspensions studied, favoured the precipitation of apatite. For 
solutions with lower final $\mathrm{pH}$, other calcium phosphates such as monetite and brushite formed in greater proportions. Minor amounts of Al- and Fe-bound $\mathrm{P}$ were also detected in the XANES samples, suggesting that $\mathrm{P}$ adsorption to $\mathrm{Al}$ and Fe oxides was not a major process affecting the $\mathrm{P}$ removal performance of AOD slag.

\section{Conclusions}

The P removal performance of AOD slag with both synthetic P solution and real wastewater was very good, showing AOD slag to be a promising alternative material for $\mathrm{P}$ removal from wastewater. It was able to remove $>97 \%$ of $\mathrm{P}$ from a synthetic solution in around 4 hours and $88 \%$ of $\mathrm{P}$ from wastewater in 22 hours. At a dose of $25 \mathrm{~g}$ AOD slag $\mathrm{L}^{-1}$ wastewater, a PRE of $90 \%$ was achieved in 8 hours. AOD slag suspended in synthetic P solution exhibited a maximum PRC of $27.47 \mathrm{mg} \mathrm{P} \mathrm{g}^{-1}$, which was higher than the values reported for EAF and BOF slags. Treatment with PEG improved PRE by $47.9 \%$ for fine AOD particles. The P removed by PEGtreated slags was dominated by some type of amorphous Ca phosphate not covered by the mineral standards used in this research. Visual MINTEQ analysis and XANES results together showed that the main P removal mechanism was precipitation of calcium phosphate. It was found that highly alkaline solution conditions favoured formation of apatite, while neutral $\mathrm{pH}$ contributed to the presence of brushite. Batch experiments showed that these P precipitates could be easily removed by filtering the suspension. This might be an attractive feature for P recovery from wastewater.

Further investigations on P recovery from the white precipitates and used AOD slag will be conducted and research efforts to improve the P removal rate and capacity of AOD slag are ongoing. 


\section{Acknowledgments}

The China Scholarship Council (CSC) is sincerely thanked for a doctorate scholarship. The AOD slag and data on its chemical composition were provided by the company Outokumpu Stainless AB, Sweden. Steve Hillier of the James Hutton Institute, Aberdeen, is acknowledged for providing mineral standards. Thanks to Dean Hesterberg, Ann Kristin Eriksson, Frank Schmieder and David Eveborn for preparing standards and for acquiring some of the spectra. Wantana Klysubun and the staff at BL-8, SLRI, Thailand, are thanked for support and organisation of the beamline. This study formed part of the I-slag project, sponsored by Vinnova.

\section{References}

Ali, M. E., Lamprecht, A., 2013. Polyethylene glycol as an alternative polymer solvent for nanoparticle preparation. International Journal of Pharmaceutics 456(1), 135-142.

Ali, M. I., Schneider, P. A., 2006. A fed-batch desigh approach of struvite system in controlled supersaturation. Chemical Engineering Science 61(12),3951-3961.

Asuman, K., Beklioğlu, E. M. and Demirer, G. N., 2007. Use of blast furnace granulated slag as a substrate in vertical flow reed beds: Field application. Bioresource Technology 98(11), 2089-2101.

Barca, C., Gérente, C., Meyer, D., Chazarenc, F. and Andrès, Y., 2012. Phosphate removal from synthetic and real wastewater using steel slags produced in Europe. Water Research 46(7), 2376-2384.

Bare, S., 2005. XANES Measurements and Interpretation. http://cars9.uchicago.edu/xafs_school/APS_2005/Bare_XANES.pdf

Beauchemin, S., Hesterberg, D., Chou, J., Beauchemin, M., Simard, R. R., and Sayers, D. E., 2003. Speciation of phosphorus in phosphorus-enriched agricultural soils using X-Ray Absorption Near-Edge Structure Spectroscopy and chemical fractionation. Environ. Qual. 32,1809-1819.

Blöcher, C., Niewersch, C. and Melin, T., 2012. Phosphorus recovery from sewage sludge with a hybrid process of low pressure wet oxidation and nanofiltration. Water Research 46(6), 2009-2019.

Bowden, L. I., Jarvis, A. P., Younger, P. L., and Johnson, K. L., 2009. Phosphorus removal from waste waters using basic oxygen steel slag. Environ. Sci. Technol. 43(7), 2476-2481.

Chen, Y., Randall, A., McCue, T., 2004. The efficiency of enhanced biological phosphorus removal from real wastewater affected by different ratios of acetic to propionic acid. Water Research 38(1), 27-36.

Christoffersen, M.R., Christoffersen, J., Kibalczyc, W., 1990. Apparent solubilities of two amorphous calcium phosphates and of octacalcium phosphate in the temperature range $30-42^{\circ} \mathrm{C}$. J. Crystal Growth 106, 349-354.

Claveau-Mallet, D., Wallace, S. and Comeau, Y., 2013. Removal of phosphorus, fluoride and metals from a 
gypsum mining leachate using steel slag filters. Water Research 47(4), 1512-1520.

Drizo, A., Forget, C., Chapuis, R. P. and Comeau, Y., 2006. Phosphorus removal by electric arc furnace steel slag and serpentinite. Water Research 40(8), 1547-1554.

Engström, F., Larsson, M. L., Samuelsson, C. Sandström, Å., Robinson, R. and Björkman, B., 2014. Leaching behavior of aged steel slags. Steel Research International 85(4), 607-615.

Eveborn, D., Gustafsson, J. P., Hesterberg, D., Hillier, S., 2009. XANES Speciation of P in environmental samples: An assessment of filter media for on-site wastewater treatment. Environ. Sci. \& Technol. 43(17), 6515-6521.

García-Jimeno, S. and Estelrich, J., 2013. Ferrofluid based on polyethylene glycol-coated iron oxide nanoparticles: Characterization and properties. Colloids and Surfaces A: Physicochemical and Engineering Aspects 420(0), 74-81.

Gong, G., Ye, S., Tian, Y., Wang, Q., Ni, J. and Chen, Y., 2009. Preparation of a new sorbent with hydrated lime and blast furnace slag for phosphorus removal from aqueous solution. Journal of Hazardous Materials 166(23),714-719.

Guan, W., Ji, F., Chen, Q., Yan, P. and Pei, L., 2013. Synthesis and Enhanced Phosphate Recovery Property of Porous Calcium Silicate Hydrate Using Polyethyleneglycol as Pore-Generation Agent. Materials 6(7), 28462861.

Guan, W., Ji, F., Fang, Z., Fang, D., Cheng, Y., Yan, P.and Chen, Q., 2014. Low hydrothermal temperature synthesis of porous calcium silicate hydrate with enhanced reactivity SiO2. Ceramics International 40(3), 4415-4420.

Gustafsson, J. P., 2014. Visual MINTEQ 3.1. Retrieved 05-05, 2014, from http://www2.lwr.kth.se/English/Oursoftware/vminteq/download.htmL.

Gustafsson, J. P., Renman, A., Renman, G., and Poll, K., 2008. Phosphate removal by mineral-based sorbents used in filters for small-scale wastewater treatment. Water Research 42(1-2), 189-197.

Hendon, C., H., Colonna-Dashwood, L., Colonna-Dashwood, M., 2014. The Role of Dissolved Cations in Coffee Extraction. J. Agric. Food Chem., 62(21):4947-4950.

Hosokawa, M., Yoshikawa, T., Tanaka, T., Yamasaki, N., 2014. Surface Reaction of Blast Furnace Slag under Hydrothermal Conditions. ISIJ International, 54(3), 548-552.

Huaiwei, Z., Xin, H., 2011. An overview for the utilization of wastes from stainless steel industries. Resources, Conservation and Recycling 55(8), 745-754.

Jing, Z., Jin, F., Hashida, T., Yamasaki, N., Ishida, H., 2007. Hydrothermal solidification of blast furnace slag by formation of tobermorite, Journal of Materials Science 42(19), 8236-8241.

Johansson, L., 2010. Industrial By-products and natural substrata as phosphorus sorbents. Environmental Technology 20(3), 309-316.

Johansson Westholm, L., 2010. The use of blast furnace slag for removal of phosphorus from wastewater in Sweden-a review. Water 2(4), 826-837.

Kim, E.H., Yim, S.B., Jung, H.C., and Lee, E.J., 2006. Hydroxyapatite crystallization from a highly concentrated phosphate solution using powdered converter slag as a seed material. Journal of Hazardous Materials 136(3), 690-697. 
Klysubun, W., Sombunchoo, P., Deenan, W., and Kongmark, C., 2012. Performance and status of beamLine BL8 at SLRI for X-ray absorption spectroscopy. Journal of Synchrotron Radiation 19(6), 930-936.

Kostura, B., Kulveitová, H., and Leško, J., 2005. Blast furnace slags as sorbents of phosphate from water solutions. Water Research 39(9), 1795-1802.

Kriskova, L., Pontikes, Y., Cizer, Ö., Mertens, G., Veulemans, W., Geysen, D., Jones, P. T., Vandewalle, L., Van Balen, K., and Blanpain, B. 2012. Effect of mechanical activation on the hydraulic properties of stainless steel slags. Cement and Concrete Research 42(6), 778-788.

McDowell, H., Gregory, T.M., Brown, W.E., 1977. Solubility of $\mathrm{Ca}_{5}\left(\mathrm{PO}_{4}\right)_{3} \mathrm{OH}$ in the system $\mathrm{Ca}(\mathrm{OH})_{2}-\mathrm{H}_{3} \mathrm{PO}_{4}-$ $\mathrm{H}_{2} \mathrm{O}$ at $5,15,25$, and $37^{\circ} \mathrm{C}$. Journal of Research of the National Bureau of Standards 81A, 273-281.

Motz, H., Geiseler, J., 2001. Products of steel slags an apportunity to save natural resources. Waste Management 21(3), 285-293.

Nilsson, C., Renman, G., Johansson, L., Renman, A., and Drizo, A., 2013. Effect of organic load on phosphorus and bacteria removal from wastewater using alkaline filter materials. Water Research 47(16), 6289-6297.

Oguz, E., 2004. Removal of phosphate from aqueous solution with blast furnace slag. Journal of Hazardous Materials 114(1-3), 131-137.

Oxmann, J.F. 2014. Technical note: an X-ray absorption method for the identification of calcium phosphate species using peak height ratios. Biogeosci. 11, 2169-2183.

Petzet, S., Peplinski, B., and Cornel, P., 2012. On wet chemical phosphorus recovery from sewage sludge ash by acidic or alkaline leaching and an optimized combination of both. Water Research 46(12), 3769-3780.

Prietzel, J., Dümig, A., Wu, Y, Zhou, J., Klysubun, W. 2013. Synchrotron-based P K-edge XANES spectroscopy reveals rapid changes in phosphorus speciation in the topsoil of two glacier foreland chronosequences. Geochim. Cosmochim. Acta 108, 158-171.

Rastas, L., Hedström, A., 2006. Methodological aspects of using blast furnace slag for wastewater phosphorus removal. Journal of Environmental Engineering 132(11), 1431-1438.

Ravel, B., 2009. Athena User’s Guide.

Ravel, B. and Newville, M., 2005. ATHENA, ARTEMIS, HEPHAESTUS: data analysis for X-ray absorption spectroscopy using IFEFFIT. Journal of Synchrotron Radiation 12(4), 537-541.

Reijnders, L., 2014. Phosphorus resources, their depletion and conservation, a review. Resources, Conservation and Recycling 93, 32-49.

Santos, R. M., François, D., Mertens, G., Elsen, J., and Van Gerven, T., 2013a. Ultrasound-intensified mineral carbonation. Applied Thermal Engineering 57(1-2), 154-163.

Santos, R. M., Van Bouwel, J., Vandevelde, E., Mertens, G., Elsen, J., and Van Gerven, T., 2013b. Accelerated mineral carbonation of stainless steel slags for CO2 storage and waste valorization: Effect of process parameters on geochemical properties. International Journal of Greenhouse Gas Control 17, 32-45.

Shen, H., and Forssberg, E., 2003. An overview of recovery of metals from slags. Waste Management 23(10), 933-949.

Shilton, A. N., Elmetri, I., Drizo, A., Pratt, S., Haverkamp, R. G., and Bilby, S. C., 2006. Phosphorus removal by an 'active' slag filter-a decade of full scale experience. Water Research 40(1), 113-118.

Smith, R.M., Martell, A.E., Motekaitis, R.J., 2003. NIST Critically Selected Stability Constants of Metal 
Complexes Database. Version 7.0. NIST Standard Reference Database 46. National Institute of Standards and Technology, US Department of Commerce, Gaithersburg.

Song, Y., Hahn, H. H., Hoffmann, E., 2002. Effects of solution conditions on the precipitation of phosphate for Recovery A thermodynamic evaluation. Chemosphere 48 (10), 1029-1034.

Tannazi, F., and Bunker, G., 2005. Determination of Chemical Speciation by XAFS. Physica Scripta 115,953956.

Van Vooren, L., Lessard, P., Ottoy, J., 1999. pH buffer capacity based monitoring of algal wastewater treatment. Environmental Technology 20(6), 547-561.

Wouter, J. J. Huijgen, Comans, Rob N. J., 2006. Carbonation of Steel Slag for $\mathrm{CO}_{2}$ sequestration: Leaching of products and reaction mechanisms. Environ. Sci. Technol. 40, 2790-2796. 